\title{
Implementation Of Patient Safety at Ibuh Primary Health Care in Payakumbuh City
}

\author{
Dien Gusta Anggraini Nursal ${ }^{1}$, Rizanda Machmud ${ }^{2}$, Raja Zila Santia Anggela ${ }^{3}$ \\ \{diennursal@fkm.unand.ac.id ${ }^{1}$, rizanda_machmud@yahoo.com², zilaraja29@gmail.com ${ }^{3}$ \} \\ Faculty of Public Health, Universitas Andalas, Padang, Indonesia ${ }^{1}$ \\ Faculty of Medicine, Universitas Andalas, Padang, Indonesia ${ }^{2}$ \\ Ibuh Primary Health Care, Payakumbuh, Indonesia ${ }^{3}$
}

\begin{abstract}
Patient safety is important in patient care, especially in primary health care as the first health care providers. The implementation of patient safety at Indonesian's primary health care still varies because there is no specific assessment model. There has been no official report on the incidence of patient safety, but from the primary health care accreditation report, the highest incidence was found in Payakumbuh primary health care, so that the implementation of patient safety at Ibuh primary health care and the factors that influenced must be examined. The study was conducted in December 2017 with a cross section design. Samples were taken with total sampling as much 51 repondents at ibuh primary health care. The data was taken using a valid and reliable questionnaire about patient safety and the factors that influence it. Data were analyzed using chi square test with $95 \%$ confidence degree. It was found that $47.1 \%$ of respondents have carried out poor patient safety, $47.1 \%$ have bad leadership, $45.1 \%$ have bad policy, $45.1 \%$ bad incident detection, $41.2 \%$ have poor mitigation, $45.1 \%$ have dissatisfied patients, $47.1 \%$ poor commitment of patients, $49 \%$ excessive staff workload, $47.1 \%$ lack of staff commitment, $49 \%$ bad risk grading, 49\% RCA and FMEA not done, and 49\% internal audit not good. All variables are significantly related to patient safety. It is recommended that primary health care more improve patient safety by improving leadership, policy, incident detection and mitigation. Giving appreciation for motivating staff and using social media to increases patient satisfaction and commitment.
\end{abstract}

Keywords: Patient safety, Primary Health, BENOC

\section{Introduction}

Don Brown, Owner, Director of Software Products and Services for BasicSafe Says that the incident was just the tip of the Iceberg, a sign of a much bigger problem below the surface. The problem that appears is only small, but there are big problems below that have not been revealed. Top of the iceberg mountain is Patient safety incidents. The bigger problem below the surface occurs because of a system defect or system error in the implementation of the health care system. This error can be in the form of Poor design, Incorrect installation, faulty maintenance, Poor purchasing decisions and Inadequate staffing [1].

Institute of Medicine (IOM) reported the adverse event as 2,9\% and 6,6\% of the event are die. This made patient safety become as a central issue and new health care agenda in many countries [2]-[4]. Patient safety develops in a hospital setting earlier [5]-[7]. But, concern for patient safety in the Community Health Center (CHC) start to grow in recent years [8],[9]. 
Based on IOM reported, the number for an adverse event in New York is 3,7\% where 16,6\% died. For the entire US, mortality due to an adverse event among hospitalized patient amounting to 33,6 million per year [3],[10]. In Indonesia, adverse event report by Medical Care and Nursing, Ministry of Health reached the 289 reports until February 2016 [11].

Adverse event cases in CHC are 0.004 to 240 per 1,000 consultations [12]. The current study which is conducted in CHC found that adverse event often related to administrative issues and documentation [12],[13] diagnoses of disease and drugs prescription [14],[15] cooperation and communication between health workers [14], [15],[17] reporting and monitoring [13],[18].

Patient safety aspect appeared apart of the Health Minister Regulation number 75 of 2014 on Standards for Public Health Care (CHC) Accreditation at the end of 2017 state that all health centers in Indonesia must have been accredited [19],[20]. The readiness of public health care in the new health center has been reached $71 \%$ and service of non-communicable diseases has reached $79 \%$. Only $24 \%$ of health centers could implement all components of the diagnosis [11].

Until now, the report of patient safety incidents in $\mathrm{CHC}$ and the Indonesian Health Department has not been found, that made the lack of knowledge about the magnitude of the problems faced. But the news that appeared in the local newspaper about the malpractice incident shows that the problem of patient safety occurred in $\mathrm{CHC}$.

Safety and rights of the patient and the patient's family is the approach used by primary health care for ensuring the improvement of quality and performance improvement and risk management are assessed by external parties using a standard set (accreditation) [21] One of the efforts to improve the quality of primary health care is development primary health care that capable of Basic Emergency Neonatal Obstetry Care (BENOC). With the BENOC, pregnant and neonatal mothers who are under their authority can be appointed at the primary health care [22]. In providing services to BENOS primary health care patients must also pay attention to patients who can contribute to reducing maternal and neonatal death.

Patient safety also plays a role in the effort to reduce Maternal Mortality Rate (MMR) and Infant Mortality Rate (IMR). In 2012 the highest maternal mortality rate in Indonesia compared to developing countries in Asia and showed a significant increase in MMR that be 359 maternal deaths every 100,000 live births. MMR again showed a decline to 305 maternal deaths every 100,000 live births based on SUPAS in 2015 [23]. MMR in West Sumatra in 2015 as much as 115 each 100.000 live death (111 persons), while in 2016 as many as 114 each 100,000 births life (107) [24],[25]. MMR in Payakumbuh in 2016 was as much as 72.4 every 100,000 live births ( 2 people). This figure shows that the MMR PHC Ibuh included in the five lowest among the 19 districts/cities in West Sumatra [26].

The health condition of the child until now there has been as expected. Based on the 2012 Demographic and Health Survey, IMR 32 every 1,000 live births and children under five-year mortality rate still 40 every 1,000 live births. Target MDG's by 2015, IMR decreased to 23 every 1,000 live births, children under five-year mortality rate dropped to 32 every 1,000 live births [27]. IMR in West Sumatra in 2016 was 7 every 1,000 live births (700) or while IMR in Payakumbuh as much as 6.88 every 1,000 live births (19 people) [25],[26].

To decrease MMR and IMR, deliveries have to pay attention to patient safety. In 2016, coverage births attended by skilled health personnel in West Sumatra by $83 \%$ and Payakumbuh is one of the cities in West Sumatra which has primary health care Basic Emergency Neonatal Obstetric Services the scope of births attended by skilled health personnel the third highest after the city of Padang and Pariaman, accounting for 92\% [25],[26]. With high coverage, childbirth assistance will affect the workload of staff and commitment of the staff that might impact on patient safety. 
Handling of obstetric and newborn complications is urgently needed to reduce MMR and IMR and in implementation should pay attention to patient safety. Percentage of handling obstetric complications in West Sumatra in 2016 amounted to $75.75 \%$ and amounted to $44.8 \%$ of neonatal complications. Payakumbuh included in the scope of services of obstetric complications is the highest among all 12 districts/cities in West Sumatra by $78 \%$ [25. Treatment of complications is an important role of basic emergency primary health care following its authority. In the implementation of the handling of this complication remains should always pay attention to the safety of the patient so that the patient safety incident rate can be lowered.

At the Basic Emergency Neonatal Obstetric Services in primary health care Payakumbuh namely Ibuh Primary Health Care and Lampasi Primary Health Care, patient safety incident data obtained in 2015 three cases in Ibuh Primary Health Care and three cases in Lampasi Primary Health Care. All patient safety incidents are not related to patient care Basic Emergency Neonatal Obstetric Services. Whereas in 2016, Ibuh Primary Health Care patient safety incidents as much as ten cases and eight cases were a patient safety incident Basic Emergency Neonatal Obstetric Services. While at the Primary Health Care Lampasi much as two cases and one case of patient safety incidents Basic Emergency Neonatal Obstetric Services. The implementation of patient safety at the primary health care requires good performance from all parties so that the patient's safety induced can be reduced - Healthcare Model Malcolm Baldrige Criteria for Performance Criteria (MBHCP) that can be used to measure and provide feedback on the performance of the organization in making quality health services and be competitive in the global market. MBHCP has advantages because it can be used to provide an overall assessment of the organization in an integrated aspect.[29]

Nursal (2017) reported that there are no guidelines about patient safety from Department of Health of West Sumatera to the BENOC Health Center, it is also obtained that the patient safety incident that occurs is in the form of patient falls, diagnostic errors and drug delivery personally without reporting to the Department of Health. In another research Nursal (2018) reported in the variable Model Patient Safety by Malcolm Baldrige in primary health care Basic Emergency Neonatal Obstetric Services was found that all of the variables that consists of leadership, policy, detection of incidents, mitigation, patient satisfaction, commitment to patients, risk grading, RCA and FMEA, the workload of the staff, the commitment of staff and internal audit of the patients's safety associated with a significantly (p-value $=0.0001)$.[28],[29]

Based on the problems and see the importance of patient safety in the primary health care in order to improve maternal and child health $(\mathrm{MCH})$, researchers interested in studying "Factors associated with patient safety in the primary health care Basic Emergency Neonatal Obstetric Services Ibuh Payakumbuh" because of the preliminary study Primary Health Care Ibuh has a number of incidents highest patient safety compared to another basic emergency primary health care in Payakumbuh

\section{Method}

The study used cross-sectional design. The study population was the entire staff primary health care, the sample is taken using total sampling technique to get a sample of 51 people, this research using a measuring instrument questionnaire adopted from research Nursal (2017) entitled the development of models of patient safety based on Malcolm Baldrige in primary health care Basic Emergency Neonatal Obstetric Services in the implementation of safety mother and daughter consisting of questions about leadership, policy, incident detection, 
mitigation, patient satisfaction, patient commitment, risk grading, RCA and FMEA, the workload of the staff, the commitment of staff, internal audit and safety results of patients by measuring the questionnaire. Data were analyzed using univariate, bivariate with Fisher exact and multivariate with regression logistic.

\section{Results}

The results of the normal test analysis of the data, it was found that all data were not normally distributed, so for categorization carried out using the median.

The results showed less than half of the respondents with less good safety results of patients $(47.1 \%)$, poor leadership $(47.1 \%)$, poor policies $(45.1 \%)$, incident detection unfavorable $45.1 \%$, mitigation $41.2 \%$ less good, less good patient satisfaction $45.1 \%$, committed $47.1 \%$ of patients are less good, less good staff workload $49 \%$, less staff commitment well (47.1\%), risk grading less well (49\%), RCA and FMEA unfavorable (49\%), lack of good internal audit (49\%).

Table 1. Frequency Distribution of Patient Safety and Variables Related

\begin{tabular}{|c|c|c|}
\hline Variables & $\mathrm{f}$ & $\%$ \\
\hline \multicolumn{3}{|c|}{ Patient Safety } \\
\hline Not good & 24 & 47,1 \\
\hline Well & 27 & 52,9 \\
\hline \multicolumn{3}{|c|}{ Leadership } \\
\hline Not good & 24 & 47,1 \\
\hline Well & 27 & 52,9 \\
\hline \multicolumn{3}{|l|}{ Policy } \\
\hline Not good & 23 & 45,1 \\
\hline Well & 28 & 54,9 \\
\hline \multicolumn{3}{|c|}{ Incident Detection } \\
\hline Not good & 23 & 45,1 \\
\hline Well & 28 & 54,9 \\
\hline \multicolumn{3}{|l|}{ Mitigation } \\
\hline Not good & 21 & 41,2 \\
\hline Well & 30 & 58,8 \\
\hline \multicolumn{3}{|c|}{ Patient Satisfaction } \\
\hline Not good & 23 & 45,1 \\
\hline Well & 28 & 54,9 \\
\hline \multicolumn{3}{|c|}{ Commitment to Patients } \\
\hline Not good & 24 & 47,1 \\
\hline Well & 27 & 52,9 \\
\hline \multicolumn{3}{|c|}{ Workload Staff } \\
\hline Not good & 25 & 49 \\
\hline Well & 26 & 51 \\
\hline \multicolumn{3}{|c|}{ The commitment of staff } \\
\hline Not good & 24 & 47,1 \\
\hline Well & 27 & 52,9 \\
\hline \multicolumn{3}{|c|}{ Risk Grading } \\
\hline Not good & 25 & 49 \\
\hline Well & 26 & 51 \\
\hline \multicolumn{3}{|c|}{ RCA and FMEA } \\
\hline Not good & 25 & 49 \\
\hline Well & 26 & 51 \\
\hline \multicolumn{3}{|c|}{ Internal audit } \\
\hline Not good & 25 & 49 \\
\hline Well & 26 & 51 \\
\hline
\end{tabular}


From the analysis of responses to questionnaires leadership variable to the percentage of respondents are most often provide support resources for each of the repair/improvement of patient safety by $62.7 \%$. Detection of incidents with the highest percentage of respondents' answers are often expensive inputs (suggestions and ideas) staff in making the detection of incidents in primary health care Basic Emergency Neonatal Obstetric Services by $66.7 \%$ and patient satisfaction with the highest percentage of respondents answer is always the availability of suggestion boxes for grievances and suggestions of patients and often perform measurements of patient satisfaction level of $62.7 \%$.

Statistical analysis was obtained variables of leadership, policy, incident detection, mitigation of patient satisfaction, patient commitment, the workload of the staff, the commitment of staff, risk grading, RCA and FMEA and internal audit related to the safety of patients $\mathrm{p}=0.001(<0.05)$ can be seen in the table 2 .

Tabel 2 Relationship with Dependent Variables Independent Variables

\begin{tabular}{|c|c|c|c|c|c|c|c|c|}
\hline \multirow{3}{*}{ Independent Variable } & \multicolumn{6}{|c|}{ Patient Safety } & \multirow{3}{*}{$\begin{array}{l}\mathrm{PR} \\
(95 \% \mathrm{CI})\end{array}$} & \multirow{3}{*}{$\mathrm{p}$-value } \\
\hline & \multicolumn{2}{|c|}{ Less } & \multicolumn{2}{|c|}{ Well } & \multicolumn{2}{|c|}{ Total } & & \\
\hline & $\mathrm{f}$ & $\%$ & $\mathrm{f}$ & $\%$ & $\mathrm{f}$ & $\%$ & & \\
\hline \multicolumn{9}{|l|}{ Leadership } \\
\hline Not good & 19 & 79,2 & 5 & 20,8 & 24 & 100 & \multirow{3}{*}{$\begin{array}{l}17 \\
(4,193-66,667)\end{array}$} & \multirow{3}{*}{0,001} \\
\hline Well & 5 & 18,5 & 22 & 81,5 & 27 & 100 & & \\
\hline \multicolumn{7}{|l|}{ Policy } & & \\
\hline Not good & 17 & 73,9 & 6 & 26,1 & 23 & 100 & 9 & \multirow{2}{*}{0,001} \\
\hline Well & 7 & 25 & 21 & 75 & 28 & 100 & $(2,401-30,089)$ & \\
\hline \multicolumn{9}{|l|}{ Incident Detection } \\
\hline Not good & 19 & 82,6 & 4 & 17,4 & 23 & 100 & \multirow{3}{*}{$\begin{array}{l}22 \\
(5,134-93,09)\end{array}$} & \multirow{2}{*}{0,001} \\
\hline Well & 5 & 17,9 & 23 & 82,1 & 28 & 100 & & \\
\hline \multicolumn{8}{|l|}{ Mitigation } & \\
\hline Not good & 16 & 76,2 & 5 & 23,8 & 21 & 100 & 9 & \multirow[b]{2}{*}{0,001} \\
\hline Well & 8 & 26,7 & 22 & 73,3 & 30 & 100 & $(2,401-31,957)$ & \\
\hline \multicolumn{9}{|l|}{ Patient Satisfaction } \\
\hline Not good & 19 & 82,6 & 4 & 17,4 & 23 & 100 & \multirow{2}{*}{$\begin{array}{l}22 \\
(5,134-93,0)\end{array}$} & \multirow{2}{*}{0,001} \\
\hline Well & 5 & 17,9 & 23 & 82,1 & 28 & 100 & & \\
\hline \multicolumn{9}{|c|}{ Commitment to Patients } \\
\hline Not good & 19 & 79,2 & 5 & 20,8 & 24 & 100 & \multirow{2}{*}{$\begin{array}{l}17 \\
(4,193-66,667)\end{array}$} & \multirow{2}{*}{0,001} \\
\hline Well & 5 & 18,5 & 22 & 81,5 & 27 & 100 & & \\
\hline \multicolumn{9}{|l|}{ Workload Staff } \\
\hline Not good & 21 & 84 & 4 & 16 & 25 & 100 & \multirow{3}{*}{$\begin{array}{l}40 \\
(8,049-201,3)\end{array}$} & \multirow{3}{*}{0,001} \\
\hline Well & 3 & 11,5 & 23 & 88.5 & 26 & 100 & & \\
\hline \multicolumn{7}{|c|}{ The commitment of staff } & & \\
\hline Not good & 19 & 79,2 & 5 & 20,8 & 24 & 100 & 17 & \\
\hline Well & 5 & 18,5 & 22 & 81,5 & 27 & 100 & $(4,193-66,7)$ & 0,001 \\
\hline Risk Grading & & & & & & & & \\
\hline Not good & 21 & 84 & 4 & 16 & 25 & 100 & 40 & $\Omega 0 \Omega 1$ \\
\hline Well & 3 & 11,5 & 23 & 88,5 & 26 & 100 & $(8,049-201,3)$ & 0,001 \\
\hline RCA and FMEA & & & & & & & & \\
\hline Not good & 21 & 84 & 4 & 16 & 25 & 100 & 40 & \\
\hline Well & 3 & 11,5 & 23 & 88,5 & 26 & 100 & $(8,049-201,3)$ & 0,001 \\
\hline Internal audit & & & & & & & & \\
\hline Not good & 22 & 88 & 3 & 12 & 25 & 100 & & \\
\hline Well & 2 & 7,7 & 24 & 92,3 & 26 & 100 & $(13,4-576,9)$ & 0,001 \\
\hline
\end{tabular}




\section{Discussion}

The results showed that less than half of the respondents with less good safety results of patients (47.1\%). In the analysis of responses to questionnaires on patient safety variables with the highest percentage of respondents is always decreasing case unexpected events / KTD (one identity, one check, one drug, patient falls, etc.) in a patient. Follow-up of incidents that have occurred conducted by the event, for example, to follow up the incident in 2016 on the incidence of patients almost fell submit to the head of the primary health care for the procurement of disposable bed railing. Follow-up for incident conducted repair of the exchanged recipes patient identification method by adding the complete data address, date of birth and where mothers prescribed.

Univariate analysis showed that less than half of the respondents with less good leadership $(47.1 \%)$. It is seen by leaders who often provide support resources for each of the repair/improvement of patient safety, always encourage staff to report any patient safety incidents encountered, and often creates a two-way communication with the entire staff to deliver patient safety in the primary health care Basic Emergency Neonatal Obstetric Services. In bivariate analysis shows that there is a relationship of leadership and patient safety. This study is consistent with other research (Anwar et al., 2014) which concluded that there is a significant relationship between effective leadership Head Space with patient safety culture implementation [30]. So also with the research (Nivalinda, et al., 3013) which states that there is influence between leadership style headspace of the application of patient safety culture [31]. Leadership will support the increased efforts of patient safety are needed to improve patient safety and reduce the incidence of unexpected [11]. It is because the leadership has the authority in decision-making and can influence and direct the staff to do the work in improving patient safety.

Univariate analysis showed that less than half of the respondents with poor policies $(45.1 \%)$. It is seen by policy always encourage staff to continue to improve and enhance the safety of patients and often create an environment that stimulates learning organizations patient safety for all staff to provide the best service. In bivariate analysis showed that there are relationships and patient safety policy. This study is in line with research (Nursal, 2017) which states there is a significant relationship between policy and patient safety [29]. However, this study is not in line with the research (Bodur, et al., 2009) which get no relationship between support from management with patient safety in primary health care [33. The policy will affect the safety of patients, because of the presence of guidance will affect staff in acting in improving patient safety resulting in patient safety staff can have its reference.

The results showed that less than half of the respondents with unfavorable incident detection $45.1 \%$. It can be seen by considering the frequency of the input (suggestions and ideas) staff in making the detection of incidents in primary health care Basic Emergency Neonatal Obstetric Services often guarantee financial capability and resources to carry out the incident detection in primary health care, and often planning and improvements to minimize the incident. The results showed that the correlation detection and patient safety incidents. This study is in line with research (Nursal, 2017) which states there is a significant relationship between incident detection with patient safety [29]. Incident detection efforts made by an early vote on matters that may pose a danger to the safety of patients. Thus, it can be done early prevention of the occurrence of security incidents in the patient, so that further mitigation can be done to reduce or eliminate the risk of these dangers.

Mitigation variable gain that is less than half of the respondents to the mitigation of unfavorable $41.2 \%$. This is seen often establish effective communication between the heads of 
primary health care with staff and fellow staff at the primary health care Basic Emergency Neonatal Obstetric Services, often there is a learning and development in the primary health care staff on a regular basis and there is a change of behavior Basic Emergency Neonatal Obstetric Services patient safety after learning. From the bivariate analysis shows that there are relationship mitigation and safety of patients, this study is in line with research (Nursal, 2017) which states there is a significant relationship between mitigation with patient safety [29]. One form of mitigation is to establish effective communication between the heads of primary health care with staff and fellow staff at the primary health care Basic Emergency Neonatal Obstetric Services, As Parker [2015) states the communication within the team is very important and affect the safety of patients, with effective communication will reduce the risk of errors in the work [34]. Also, the need for the development of learning and development staff on a regular basis because it will be able to increase the knowledge of staff. With a high knowledge staff then it will minimize the risk of the incident or eliminated.

The results showed that less than half of the respondents with poor patient satisfaction at $45.1 \%$. This can be seen with the suggestion box is always available to accommodate the patient's complaints and suggestions, often making measurements of patient satisfaction levels, as well as the services provided, are always expected to exceed the expectations of patients. The results showed that there is a relationship between patient satisfaction and patient safety. This study is in line with research (Nursal, 2017) which states that there is a significant relationship between patient satisfaction with patient safety $(\mathrm{P}$-value $=0.0001) .(29))$. Likewise, research (Cabello et al., 2016) suggests the provision of high-quality clinical care experienced by patients have a strong influence on patient safety [35. Patients as nursing care service users require nursing care following their rights, namely the quality of nursing care. Measuring the level of patient satisfaction need to be done, such as using a suggestion box. Social media can also be used to measure patient satisfaction, as their social media accounts specialty clinic so that patients can submit complaints and suggestions. Results of univariate analysis found that less than half of respondents with poor patient commitment $47.1 \%$, from analysis of the questionnaires shows the frequency response forged cooperative relationships (partnerships) are good with patients to improve patient safety process, showing empathy toward patients and their families in giving services, perform repair/improvement of service quality continues to meet the patient's expectations. The results showed that the study is in line with research (Nursal, 2017) which states there is a significant relationship between the patient's commitment to patient safety $(\mathrm{P}$-value $=0.0001)$ [29]. In one aspect of the patient's commitment are communication and good and accurate information for patients. According to the study (Cabello et al, 2016) suggests an effective communication can have a number of positive consequences, such as preventing the possibility of adverse events, reduced psychological distress for patients, improve patient satisfaction, misinterpret or reduce the likelihood of a diagnosis or the wrong treatment, and reduce the potential for malpractice cases [35]. With good patient, commitment will create a good relationship between patients and healthcare providers. Patients may also be more receptive to what is conveyed by the officer so that patient safety incidents can be reduced.

Statistical test results found that less than half of the respondents to the workload of a good $49 \%$ less staff. It is seen by always given the opportunity for each staff for a job well done and always create a safe working environment and comfortable for the primary health care staff and any staff Basic Emergency Neonatal Obstetric Services always get a description of duties and functions of each. The bivariate analysis shows that there is a relationship workload of staff and patient safety. This study is not in line with the research (Knight et al., 2013) which states that there is no relationship workload and nurse's performance in implementing patient safety [36]. However, in line with the research (Nursal, 2017) which states there is a significant relationship 
between workload staff with patient safety (P-value $=0.0001$ ) [29]. The workload is very influential on the level of patient safety. Given the high workload can affect one's concentration, thereby increasing one's own mistakes in the act and risky to cause patient safety incidents.

Univariate analysis found that less than half of the respondents to the commitment of the staff poorly $(47.1 \%)$. The results of the questionnaire answers indicate each staff is always responsible for the safety of the patient, and every staff always participate actively in improving the quality of patient safety continuously. Statistical analysis showed that there is a relationship commitment of staff and patient safety. This study is in line with research (Nursal, 2017) which states there is a significant relationship between the staff's commitment to patient safety ( $p$-value $=0.0001$ ) [29]. The seriousness attitude of staff to improve patient safety will influence behavior in the act, such as working with following standard operating procedures to avoid patient safety incidents.

Variable risk grading getting results is less than half of the respondents with unfavorable risk grading $(49 \%)$. It can be seen by the frequent establishment of patient safety indicators based on the needs and expectations of patients, the establishment of patient safety indicators that have a clear and specific size to be achieved, the patient safety indicators often the evaluation of service processes each work unit. Statistical analysis showed that there are a relationship risk grading and patient safety. This study is in line with research (Nursal, 2017) which states there is a significant relationship between risk grading with the safety of the patient $(\mathrm{P}$-value $=0.0001)$ [29]. Likewise with the research (Verstappen et al., 2015) states is a strategy of prospective risk analysis of innovative and promising to improve patient safety in primary health care [16]. Based on the grading of this risk can be determined further actions be taken by the results obtained a grade. By knowing the risk level, implementation of measures to address these risks will be appropriate, to reduce the number of patient safety incidents.

Based on the results that less than half of the respondents with RCA and FMEA unfavorable (49\%). This can be seen by the frequent establishment of patient safety services to be improved/enhanced, defining the scope of the repair/improvement of patient safety to be implemented, and often set performance indicators of patient safety is to be improved/enhanced. Statistical analysis showed that there is a relationship RCA and FMEA to the safety of the patients of this study are not in line with the research (Bodur, et al., 2009) which states there is no significant relationship between learning organization in continual improvement in patient safety [33]. RCA is done to prevent problems that have occurred so that it does not reoccur.

The results showed that less than half of the respondents with less good internal audit (49\%). It is seen by always uses the standard operating procedures (SOP) for the safety of patients, and each service is always done by staff experts and professionals in their field. The bivariate analysis shows that there is a relationship of internal audit and patient safety. This study is in line in line with the research (Gehring, 2013) which states that there is a significant association between regular team meetings with the safety of the patients (p-value $=0.01$ ) [38] Similarly, research (Rasdini, et al., 2014) states that there is a relationship significantly between supervision with the adoption of patient safety culture [39]. The process of the audit carried out from activity to ensure (verification and documentation), assess (evaluate and measure) and recommends (provide advice and input).

The results of logistic regression analysis did not find any meaningful variables $(p>0.05)$. It can be concluded that if analyzed as a whole there are no variables that have the strongest relationship compared to the other variables. All variables have a meaningful relationship if they are dependent. This could be due to the limited number of study samples that were only 51 respondents, which according to Sugiono (2012) if the research using multivariate analysis, the sample size would be at least ten times the variable number $(10 * 12=120$ samples $)$ [40]. In 
this study it cannot be done because of the limited number of health workers in the Ibuh health center, therefore in the next research, it should be done at a health center that has enough health workers or research in more than one health center.

\section{Conclusion}

Based on the purpose of the research about the factors associated with patient safety in the primary health care Basic Emergency Neonatal Obstetric Services Ibuh Payakumbuh West Sumatra in 2017 concluded that more than half the results of patient safety, leadership, regulation, detection of incidents, mitigation, patient satisfaction, commitment to the patient, the load staff work, and commitment of staff, risk grading, RCA and FMEA, and internal audit is good. There is a significant relationship between the leadership, policy, incident detection, mitigation of patient satisfaction, patient commitment, the workload of the staff, the commitment of staff, risk grading, RCA and FMEA and internal audit with patient safety. Suggestions for primary health care expected reward or punishment of the evaluation results, the use of social media to listen to the complaints and suggestions of patients and to improve the assessment and incident measurement.

\section{References}

[1] Galvan C, Bacha EA, Mohr J, Barach P. A human factors approach to understanding patient safety during pediatric cardiac surgery. Progress in Pediatric Cardiology. 2005 May 1;20(1):13-20.

[2] C. B. Jensen, "Sociology, systems and (patient) safety: knowledge translations in healthcare policy," Sociology of health \& illness, vol. 30, pp. 309-324, 2008.

[3] L. T. Kohn, J. M.Corrigan, and M. S. Donaldson, To Err are Human: Building a Safer Health System vol. 6. Washington: National Academy Press, 2000.

[4] D. M. Gaba, "Structural and organizational issues in patient safety: a comparison of health care to other high-hazard industries," California Management Review, vol. 43, pp. 83-102, 2000.

[5] K. Armstrong, H. Laschinger, and C. Wong, "Workplace empowerment and magnet hospital characteristics as predictors of patient safety climate," Journal of nursing care quality, vol. 24, pp. 55-62, 2009.

[6] K. J. Armstrong and H. Laschinger, "Structural empowerment, Magnet hospital characteristics, and patient safety culture: making the link," Journal of Nursing Care Quality, vol. 21, pp. 124-132, 2006.

[7] V. Nieva and J. Sorra, "Safety culture assessment: a tool for improving patient safety in healthcare organizations," Quality and Safety in Health Care, vol. 12, pp. ii17-ii23, 2003.

[8] S. Kirk, D. Parker, T. Claridge, A. Esmail, and M. Marshall, "Patient safety culture in primary care: developing a theoretical framework for practical use," Quality and Safety in Health Care, vol. 16, pp. 313-320, 2007.

[9] T. Wilson, M. Pringle, and A. Sheikh, "Promoting patient safety in primary care: research, action, and leadership are required," British Medical Journal, vol. 323, pp. 583-583, 2001.

[10] E. J. Thomas, D. M. Studdert, H. R. Burstin, E. J. Orav, T. Zeena, E. J. Williams, et al., "Incidence and types of adverse events and negligent

[11] Subdit Pelayanan Medis dan Keperawatan Kementrian Kesehatan RI, "Evaluasi pelaporan EReporting Pelaporan Insiden Keselamatan Pasien RS Sampai Februari 2016," presented at the Workshop Keselamatan Pasien di Hotel Horizon Bogor 2-4 Maret 2016, Bogor, 2016.

[12] M. Makeham, S. Dovey, W. Runciman, and I. Larizgoitia, "Methods and measures used in primary care patient safety research," World Health Organization., Geneva2008. 
[13] S. L.Walston, B. A. Omar, and F. A. A. Mutari, "Factors Affecting The Climate of Hospital Patient Safety," 2008.

[14] S. G. Marchon and W. V. M. Junior, "Patient safety in primary health care: a systematic review," Cad. Saude Publica, vol. 30, pp. 1815-1835, 2014.

[15] N. J. Verbakel, M. Langelaan, T. Verheij, C. Wagner, and D. L. Zwart, "Improving patient safety culture in primary care: a systematic review," J Patient Saf, 2014.

[16] S. Elrifda, "Budaya Patient Safety dan Karakteristik Kesalahan Pelayanan: Implikasi Kebijakan di Salah Satu Rumah Sakit di Kota Jambi," Kesmas: Jurnal Kesehatan Masyarakat Nasional, vol. 6, 2011.

[17] P. A. Molloy, "Examining the relationship between work climate and patient safety among nurses in acute care settings," 2012.

[18] A. Aboul-Fotouh, N. Ismail, H. EzElarab, and G. Wassif, "Assessment of patient safety culture among health-care providers at a teaching hospital in Cairo, Egypt," Eastern Mediterranean Health Journal, vol. 18, p. 372, 2012.

[19] Peraturan Menteri Kesehatan Republik Indonesia No 75 Tahun 2014 tentang Pusat Kesehatan Masyarakat, 2014.

[20] Peraturan Menteri Kesehatan Republik Indonesia Nomor 46 Tahun 2015 tentang Akreditasi Puskesmas, Klinik Pertama, Tempat Praktik Mandiri Dokter, dan Tempat Praktik Mandiri Doketr Gigi, 2015.

[21] Ministry of Health RI. PHC Accreditation Standards. Jakarta: Ministry of Health RI;2014

[22] Ministry of Health RI. Able PHC Implementation Guidelines Basic Emergency Neonatal Obstetric Services. Jakarta: Ministry of Health RI;2013.

[23] Ministry of Health RI. Health Profile of Indonesia Jakarta: Ministry of Health RI;2016.

[24] West Sumatra Health Office. Health Profile West Sumatra West Sumatra Year 2016: West Sumatra Health Office; 2017.

[25] West Sumatra Health Office. Health Profile West Sumatra West Sumatra Year 2015: West Sumatra Health Office; 2016.

[26] Health Department Payakumbuh. Health Profile Payakumbuh Year 2016. Payakumbuh.2017

[27] Ministry of Health RI. Guidelines for Integrated Reproductive Health Services in Primary Health Care Level. Jakarta: Ministry of Health RI;2015.

[28] Nursal DGA. Implementation of Patient Safety in Obstetric Primary Care Health Center Padang Based Malcolm Baldrige Performance Excellence. Journal od Primary Healthcare : Open Access Vol 7 Issue 1. 2017.

[29] Nursal DGA. Multiple Regressions of a Malcolm Baldrige's Patient Safety Models. Indian Journal of Public Health Research \& Development Vol 9 Issue 3(50-54). 2018

[30] Anwar dkk. Effective Leadership Relations Head Room With Patient Safety Culture Implementation Inpatient Hospital in Makassar. Makasar: Hasanudin University;2014

[31] Nivalinda dkk. Influence of Leadership Style Motivation Nurse And Head Space Application Against By Nurse Patient Safety Culture Implementation At the Government Hospital in Semarang. Semarang: Journal of Nursing Management PPNI; 2013.

[32] Nursal DGA. Training Module Patient Safety in Primary Health Care Basic Emergency Neonatal Obstetric Services In the implementation of the Maternal and Child Safety. Padang: Public Health Faculity Andalas University;2017.

[33] Bodur d. A survey on patient safety culture in primary healthcare services in Turkey. 2015;Volume 21, Number 5: pp.348-355.

[34] Parker dkk. Measurement tools and process indicators of patient safety culture in primary care. A mixed methods study by the LINNEAUS collaboration on patient safety in primary care. UK: European Journal of General Practice; 2015.

[35] Cabello dkk. Identifying patient-centred recommendations for improving patient safety in General Practices in England: a qualitative content analysis of free-text responses using the Patient Reported Experiences and Outcomes of Safety in Primary Care (PREOS-PC) questionnaire. UK: WILEY;2016. 
[36] Satria dkk. Relations Workload With Nurses Performance in Implementing Patient Safety Hospital 2013. Makasar: Hasanudin University;2013.

[37] Verstappen dkk. Patient safety improvement programmes for primary care. Review of a Delphi procedure and pilot studies by the LINNEAUS collaboration on patient safety in primary care. UK: European Journal of General Practice;2015.

[38] Gehring d. Safety climate and its association with office type and team involvement in primary care. 2013; Volume 25, Number 4: pp.394-402.

[39] Rasdini dkk. Application of Patient Safety Culture Relationships With Nursing Services Supervision By Nurse Executive. Makasar: Nursing Department of Health Polytechnic Makasar;2014.

[40] Sugiono. Qualitative Quantitative Research and R\&D Methods. Bandung: Alfabeta; 2012 